\title{
Facilitative and competitive interaction components among New England salt marsh plants
}

\author{
John F Bruno ${ }^{\text {Corresp., }}{ }^{1}$, Tatyana A Rand ${ }^{2}$, Nancy C Emery ${ }^{3}$, Mark D Bertness ${ }^{4}$ \\ 1 Department of Biology, University of North Carolina at Chapel Hill, Chapel Hill, North Carolina, United States \\ 2 Northern Plains Agricultural Research Laboratory, USDA-ARS, Sidney, MT, USA \\ 3 Department of Ecology and Evolutionary Biology, University of Colorado at Boulder, Boulder, CO, United States \\ 4 Department of Ecology and Evolutionary Biology, Brown University, Providence, RI, United States \\ Corresponding Author: John F Bruno \\ Email address: jbruno@unc.edu
}

Intra- and interspecific interactions can be broken down into facilitative and competitive components. The net interaction between two organisms is simply the sum of these counteracting elements. Disentangling the positive and negative components of species interactions is a critical step in advancing our understanding of how the interaction between organisms shift along physical and biotic gradients. We performed a manipulative field experiment to quantify the positive and negative components of the interactions between a perennial forb, Aster tenuifolius, and three dominant, matrix-forming grasses and rushes in a New England salt marsh. Specifically, we asked whether positive and negative interaction components: (1) are unique or redundant across three matrix-forming species (two grasses; Distichlis spicata and Spartina patens, and one rush; Juncus gerardi), and (2) change across Aster life stages (seedling, juvenile, and adult). For adult Aster the strength of the facilitative component of the matrix-forb interaction was stronger than the competitive component for two of the three matrix species, leading to net positive interactions. There was no statistically significant variation among matrix species in their net or component effects. We found little difference in the effects of $\mathrm{J}$. gerardi on Aster at later life-history stages; interaction component strengths did not differ between juveniles and adults. However, mortality of seedlings in neighbor removal plots was $100 \%$, indicating a particularly strong and critical facilitative effect of matrix species on this forb during the earliest life stages. Overall, our results indicate that matrix forming grasses and rushes have important, yet largely redundant, positive net effects onAsterperformance across its life cycle.Studies that untangle various components of interactions and their contingencies are critical to both expanding our basic understanding of community organization, and predicting how natural communities and their component parts will respond to environmental change. 
2 Facilitative and competitive interaction components among New England salt

3 marsh plants

4

5 John F. Bruno ${ }^{1,2}$, Tatyana A. Rand ${ }^{3}$, Nancy C. Emery ${ }^{4}$, and Mark D. Bertness ${ }^{5}$

$7 \quad{ }^{1}$ corresponding author

8 2Department of Biology, The University of North Carolina, Chapel Hill, NC, USA 27599-3280

$10{ }^{3}$ USDA-ARS Northern Plains Agricultural Research Laboratory, 1500 North Central Ave, 11 Sidney, MT, USA

12

13 4Department of Ecology and Evolutionary Biology, Box 0334, University of Colorado Boulder, 14 Boulder, CO, USA

15

$16{ }^{5}$ Department of Ecology and Evolutionary Biology, Brown University, Providence, RI, USA 
21 Abstract: Intra- and interspecific interactions can be broken down into facilitative and

22 competitive components. The net interaction between two organisms is simply the sum of these

23 counteracting elements. Disentangling the positive and negative components of species

24 interactions is a critical step in advancing our understanding of how the interaction between

25 organisms shift along physical and biotic gradients. We performed a manipulative field

26 experiment to quantify the positive and negative components of the interactions between a

27 perennial forb, Aster tenuifolius, and three dominant, matrix-forming grasses and rushes in a

28 New England salt marsh. Specifically, we asked whether positive and negative interaction

29 components: (1) are unique or redundant across three matrix-forming species (two grasses;

30 Distichlis spicata and Spartina patens, and one rush; Juncus gerardi), and (2) change across

31 Aster life stages (seedling, juvenile, and adult). For adult Aster the strength of the facilitative

32 component of the matrix-forb interaction was stronger than the competitive component for two

33 of the three matrix species, leading to net positive interactions. There was no statistically

34 significant variation among matrix species in their net or component effects. We found little

35 difference in the effects of $J$. gerardi on Aster at later life-history stages; interaction component

36 strengths did not differ between juveniles and adults. However, mortality of seedlings in

37 neighbor removal plots was $100 \%$, indicating a particularly strong and critical facilitative effect

38 of matrix species on this forb during the earliest life stages. Overall, our results indicate that

39 matrix forming grasses and rushes have important, yet largely redundant, positive net effects

40 on Aster performance across its life cycle. Studies that untangle various components of

41 interactions and their contingencies are critical to both expanding our basic understanding of

42 community organization, and predicting how natural communities and their component parts will

43 respond to environmental change. 


\section{INTRODUCTION}

45 Species interactions are often composed of both negative (competitive) and positive (facilitative) components (Callaway 1994, Greenlee and Callaway 1996, Callaway and Walker 1997, Claus Holzapfel and Mahall 1999, Stachowicz 2001, Crotty and Bertness 2015). The relative importance of these components is likely to shift along gradients of physical stress and consumer pressure (Altieri et al. 2007, Altieri and van de Koppel 2014, Crotty and Bertness 2015). For example, competition between common acorn barnacles for space in rocky intertidal habitats (Connell 1961) is a classic illustration of the role played by competition in determining fine-scale distribution patterns within natural communities. But at high tidal heights (Bertness 1989, Bertness et al. 1999a) and in warmer climates (Lively and Raimondi 1987, Bertness et al. 1999b, Leonard 2000), barnacle neighbors actually facilitate one another by buffering against desiccation stress. Examples from desert (Muller 1953, Niering et al. 1963), chaparral (Callaway et al. 1991), and salt marshes (Bertness and Hacker 1994, Callaway 1994) illustrate that plant interactions also commonly shift from competitive to facilitative across physical stress gradients. species interactions is limited. One specific issue that needs further exploration is how this balance changes ontogenetically across the life history stages of the interacting organisms to 61 determine the net effect of each species on the other. In many plants (Muller 1953, Niering et al. 62 1963, Callaway 1994, Bruno and Kennedy 2000, Rand 2000, Yelenik et al. 2015) and sessile invertebrates (Dayton 1975, Bertness and Grosholz 1985, Leonard 1999), recruits and juveniles depend on neighbors for early survival and growth, but as adults they may primarily compete with these same neighbors (Niering et al. 1963, Bertness and Grosholz 1985, Bertness and Yeh 1994, Callaway 1995). In this situation, common in stressful environments, facilitation of 
67 juveniles may establish clumped adult distribution patterns that are dominated by competitive

68 forces. In other cases, the situation is reversed: for example, a number of studies have found

69 stronger competitive effects at early life history stages (emergence or recruitment), with

70 interactions becoming neutral to facilitative at later life history stages (adult survival) (Thomson

71 2005, Leger and Espeland 2010, Rojas-Sandoval and Meléndez-Ackerman 2012). Additionally,

72 whether interactions are predominately competitive or facilitative at a given life stage can

73 depend strongly on the environmental context (Rand et al. 2015), e.g., the intensity of

74 physiological stress and degree of resource limitation.

75 More generally, we still know very little about how positive and negative interaction component strengths vary among species. Is species identity an important consideration or are species redundant in the positive and negative effects they exert on their neighbors and the community as a whole? The answer to this question is likely to depend on the specific mechanisms by which competition and/or facilitation operates among species, which is in turn likely to vary depending on the study system examined. For example, the effect of nurse shrubs on seedling survival and growth in Mediterranean environments have been shown to depend strongly on shrub identity, e.g., due to morphology (Kraft et al. 2014), suggesting a lack of functional redundancy among facilitators (Gómez-Aparico et al. 2004). In contrast, two sea grass species were found to have broadly similar (i.e. redundant) effects on the composition of associated fouling communities (Moore and Duffy 2016). In salt marsh plant communities, positive interactions are strongly driven by neighbors shading one another from physical stress (Bertness and Yeh 1994, Angelini et al. 2015), in which case morphologically similar species might be predicted to have similar positive effects on neighbors. However, the competitive components of these neighbor interactions will depend on 
90 the resources being competed for and the morphological and physiological adaptations of the

91 competing species. Thus, in salt marshes, the positive components of species interactions may

92 be redundant, while the competitive components may not, leading to a de-coupling of the

93 components.

94 To date, experiments separating interaction components have only been performed in a

95 few systems (Greenlee and Callaway 1996, Claus Holzapfel and Mahall 1999), and to our

96 knowledge no studies have examined how interaction components shift ontogenetically across

97 the life history of the species or with the identity of organisms in the same functional group. The

98 purpose of this study was to answer two questions related to the context-dependency of species

99 interaction components: (1) do the strength of the positive and negative components of the

100 interaction between a perennial salt marsh forb, Aster tenuifolius, and matrix forming grasses and

101 rushes, change with the identity of the matrix species (Juncus gerardi, Distichlis spicata, and

102 Spartina patens)? and (2) does the strength of these components vary with life stage of $A$.

103 tenuifolius (seedling, juvenile, and adult)?

\section{METHODS}

106 Study system: We conducted a field experiment at Nag Creek marsh on Prudence Island, Rhode

107 Island, USA $\left(41^{\circ} 37^{\prime} 41.0^{\prime \prime} \mathrm{N} 71^{\circ} 19^{\prime} 04.4^{\prime \prime} \mathrm{W}\right)$, to examine the components of interactions among

108 plant species in a southern New England salt marsh system. Nag Creek is typical of New

109 England salt marshes, which are characterized by dense stands of perennial grasses and rushes

110 which form bands, or zones, across the tidal gradient (Niering and Warren 1980, Nixon 1982,

111 Bertness and Ellison 1987). Variation in the frequency of flooding results in a strong gradient in

112 salinity and soil oxygen availability (redox potential) corresponding to tidal height (Bertness and 
113 Hacker 1994, Hacker and Bertness 1999). The seaward marsh zone is dominated by the grass

114 Spartina alterniflora, which is replaced by Spartina patens and then a rush, Juncus gerardi, with

115 increasing elevation and distance from the shoreline. Another grass, Distichlis spicata, is

116 patchily distributed within the $S$. patens and J. gerardi zones (Miller and Egler 1950, Bertness

117 and Ellison 1987). This species is generally abundant only in areas of high disturbance or

118 increased physiological stress, where competition with the zonal dominants is absent (Brewer

119 and Bertness 1996).

120 A group of less abundant halophytic forbs (herbaceous dicots) are generally found

121 interspersed within the matrix of dominant grasses and rushes. Many of these forbs experience

122 strong competitive suppression by the dominant matrix species which can limit both seedling

123 recruitment and adult plant survival and reproduction (Ellison 1987, Shumway and Bertness

124 1992, Brewer et al. 1998, Rand 2000). Under stressful conditions, however, these same grasses

125 and rushes ameliorate soil conditions and have a net facilitative effect on forbs (Bertness and

126 Shumway 1993, Bertness and Hacker 1994). Facilitation results primarily from shading of the

127 substrate by the vegetation canopy which reduces surface evaporation and the accumulation of

128 salt on the soil surface (Bertness et al. 1992, Callaway 1994), but possibly also by oxygenation

129 of the soil (Bertness 1991). The degree to which different matrix marsh species vary in their

130 competitive or facilitative effects on salt marsh forbs is not known, in part because earlier work

131 has been done within natural zone communities and did not differentiate between effects of

132 neighbor identity and tidal elevation (Hacker and Bertness 1999, Rand 2000). In addition, while

133 previous studies have examined the net effects of matrix species on forbs, the relative strengths

134 of the competitive and facilitative components of the grass-forb interaction have not been

135 quantified in this system. 
137 tolerant perennial that germinates and emerges in early spring, flowers in late fall, and produces

138 small wind-dispersed seeds following reproduction. This species is abundant in both the $S$.

139 patens and $J$. gerardi zones in New England salt marshes and is also frequently found in

140 association with D. spicata. (Brewer et al. 1998, Rand 2000). We manipulated the species

141 identity and structure of the matrix vegetation surrounding seedling, juvenile, and adult Aster

142 plants to test if the facilitative, competitive, and net interaction effects on Aster are affected by

143 neighboring plant identity, neighboring plant density, or the life stage of Aster individuals. We

144 were specifically interested in the unidirectional effects of matrix species on marsh forbs, such as

145 Aster, and not the reciprocal effects.

146 Experimental design: Our experimental design included three treatments, with individual

147 replicates of each treatment clustered spatially into blocks within each matrix species: (1) an

148 unmanipulated control, (2) a neighbor removal, and (3) a facilitation mimic that duplicates the

149 positive effects of the neighbor without any of the negative effects (Fig. 1). In control treatments,

150 vegetation was left intact. In vegetation removal treatments all above ground vegetation within

151 the $0.25 \mathrm{~m}^{2}$ plot was clipped at the substrate surface with scissors once every two weeks until

152 regrowth no longer occurred. In facilitation mimic treatments, all above ground vegetation was

153 once again removed to eliminate competition for light. Plots were then covered with $0.25 \mathrm{~m}^{2}$

154 pieces of shade-cloth that were pinned to the substrate surface using plastic staples. Shade-cloth

155 reduces soil surface evaporation to effectively mimic the facilitating effects of plant neighbors

156 (Bertness et al. 1992). Shade-cloth was spray-painted flat white to avoid soil temperature

157 increases that often occur under black cloth in the field. Light measurements above the removal

158 and facilitation mimic plots (Fig. 2) indicate light conditions did not differ between these 
159 treatments and were not meaningfully effected by the manipulation, e.g., due to greater

160 reflectance of the white shade.

161 We manipulated the identity of the matrix species, while controlling for environmental

162 context, by transplanting square plots $\left(0.25 \mathrm{~m}^{2}\right.$ in area, $50 \mathrm{~cm}$ deep $)$ of the three matrix species

163 (S. patens, J. gerardi, and D. spicata) into the J. gerardi (high marsh) zone in the Nag Creek

164 marsh during the winter of 1999. Transplanting all matrix species into a single marsh zone

165 allowed us to standardize tidal height so that any differences between species could be attributed

166 directly to neighbor identity. Thirty Spartina patens and D. spicata plots were removed and

167 placed into equal-sized holes in the $J$. gerardi zone. J. gerardi plots were lifted out of the soil

168 and then replaced to simulate transplantation. Transplanted plots were grouped into ten blocks

169 with three plots/block for D. spicata and S. patens matrix transplants and the J. gerardi plots

170 used for Aster seedlings and juvenile plants (10 blocks for each). For the J. gerardi - adult Aster

171 plots (20 blocks), we included an additional fourth treatment in each block: a thinning treatment

172 in which vegetation was thinned to $50 \%$ of its original density by clipping with scissors.

173 In mid-May of 1999, after the transplanted matrix plots had established in their new

174 locations and experimental treatments were in place, Aster individuals were collected from

175 natural populations at Nag Creek and a single target adult plant ( $>2$ true leaves) was transplanted

176 into the center of each plot of each matrix species. Seedlings were identified by the presence of

177 cotyledons, and juvenile plants were one-year-old, pre-reproductive individuals with $<2$ true

178 leaves and no cotyledons present. The mean $( \pm 1 \mathrm{SE})$ height $(\mathrm{cm})$ and dry weight $(\mathrm{mg})$ of the

179 three experimental life stages $(n=100)$ were as follows: seedling height $=0.72 \pm 0.07$, seedling

180 weight $=1.64 \pm 0.12$; juvenile height $=6.49 \pm 0.21$, juvenile weight $=24.97 \pm 1.58 ;$ adult height

$181=16.61 \pm 0.44$, adult weight $=146.45 \pm 5.27$. In the vegetation mimic treatments, Aster 
182 transplants were inserted through a slit that was made in the center of the shade-cloth, and the

183 cloth was then pinned back together around the stem using plastic staples. All Aster transplants

184 were watered for the first week after planting to minimize transplant shock, and plants that died

185 within the first two weeks after transplantation were replaced. The experiment was set up by

186 June 1, 1999 and was harvested in August 1999. Peak Aster biomass at the study site is in late

187 August / early September (Brewer et al. 1997). Thus we maximized the experimental growing

188 season, yet harvested plants before they began to drop leaves and lose biomass.

189 Salinity and light levels were quantified in each plot on July 20 and August 20, 1999, to

190 evaluate the effects of the experimental treatments on potential salt stressors and above-ground

191 competition. Salinity measurements were taken by extracting a core of peat, $3 \mathrm{~cm}$ diameter x 3

$192 \mathrm{~cm}$ deep, in each matrix plot. We pressed each sample through cotton gauze cloth and quantified

193 salinity of the extracted pore water using a hand-held $\mathrm{NaCl}$ refractometer (precision $= \pm 1 \mathrm{~g} \mathrm{~kg}^{-1}$ ).

194 Light levels were measured between 10:00 AM and 2:00 PM with a LiCor solar monitor (Model

195 1776). Instantaneous measurements $\left(\mu \mathrm{E} \mathrm{m}^{-2} \mathrm{~s}^{-1}\right)$ were taken $5 \mathrm{~cm}$ above the soil surface (the

196 height of the sensor) and above the canopy in each experimental plot. To estimate the initial

197 mass of Aster transplants, we measured the longest leaf length of each experimental Aster on

198 June 17, 1999. Longest leaf length was also measured on an additional 82 juvenile and 43 adult

199 Aster individuals that were then harvested and weighed the same month. A regression equation

200 between longest leaf length and biomass was used to estimate initial biomass of experimental

201 plants (adults: $\mathrm{y}=0.04039 \mathrm{x}-0.13501$, adjusted $\mathrm{R}^{2}=0.77$; juveniles: $\mathrm{y}=0.01433 \mathrm{x}-0.02160$,

202 adjusted $\mathrm{R}^{2}=0.76$ ). Final biomass was estimated by harvesting all experimental plants at the end

203 of August, drying them to a constant mass into a drying oven at $55^{\circ} \mathrm{C}$ for one week, and 
204 weighing each plant to the nearest milligram. Relative growth was calculated for each plant as:

205 (measured final biomass - predicted initial biomass) / predicted initial biomass.

206 We used three simple equations to calculate the positive and negative components within

207 each block:

208

209

210

\section{1}

212

213

214

215

216

217

218

219

220

221

222

$$
\begin{aligned}
& \text { strength of positive component }=\text { mimic }- \text { removal } \\
& \text { strength of negative component }=\text { control }- \text { mimic } \\
& \text { strength of net component }=\text { control }- \text { removal }
\end{aligned}
$$

Interaction strength components were calculated using both final mass and relative growth. We compared the absolute value of each interaction component among matrix species and Aster life stages with one-factor ANOVA (block was not included as a treatment since each block produces a single value for each interaction type).

\section{RESULTS}

There was little variance in light reduction across the three matrix species (Fig. 2). The experimental treatments manipulated light and salinity levels as intended. The matrix vegetation reduced light at the soil surface to just less than $20 \%$ ambient, and thinning $J$. gerardi roughly doubled the amount of available light to $\sim 40 \%$ ambient (Fig. 2). Vegetation removal resulted in a substantial increase in salinity levels from a mean of $46.8 \mathrm{~g} \mathrm{~kg}^{-1}( \pm 1.3, \mathrm{SE})$ in mimic and vegetation treatments to $71.3 \mathrm{~g} \mathrm{~kg}^{-1}( \pm 2.2)$ in vegetation removal treatments (Fig. 2). Thinning of the $J$. gerardi canopy had no significant effect on salinity and the full canopy of all three matrix species reduced salinity to similar levels (Fig. 2). Vegetation mimics were effective in increasing light transmittance to levels similar to those in removal treatments while maintaining 
226 salinity at levels similar to those within natural vegetation (Fig. 2), suggesting this treatment

227 effectively replicated the salinity reduction aspect of facilitative interaction component.

228 Due to mortality of some of the experimental Aster transplants, our sample size was

229 reduced to 9 for juvenile Aster (in J. gerardi), 8 for adult Aster in S. patens, and 14 for adult

230 Aster in J. gerardi. None of the Aster transplants in D. spicata were lost. Mortality of Aster

231 seedlings in the matrix removal treatments was $100 \%, 0 \%$ in the vegetation ("Intact") plots, and

$23258 \%$ in the facilitation mimic plots, hence seedling data could not be used in the primary

233 analysis, i.e., we could not calculate interaction component strengths for the seedling stage.

234 Initial adult Aster biomass, estimated from regression equations (described above), did not differ

235 between the three matrix species, or between neighbor manipulation treatments (Fig. 2). By the

236 end of the experiment growth varied significantly between treatments (Fig. 3). Regardless of the

237 matrix species, the strength of the positive component of the matrix-forb interaction outweighed

238 the negative component, resulting in a positive net effect of the matrix species on Aster adults

239 and juveniles (Fig 4). There was no significant variation among matrix species in their net effects

240 or interaction components, however, the negative effect of $J$. gerardi appeared negligible

241 compared to that of D. spicata (Fig. 4). Calculation of interaction component strengths based on

242 final mass and relative growth (Fig. S1) were qualitatively similar. Within the J. gerardi matrix,

243 relative growth of adult and juvenile Aster was lower in removal treatments than in mimic,

244 thinned, and control (intact vegetation) treatments, and did not differ significantly among the

245 later three treatments (Fig. 3). The effects $J$. geradi neighbors did not vary among Aster juveniles 246 and adults.

\section{DISCUSSION}


249 Our results indicate that the net effect of matrix species on forbs consists of both positive and

250 negative components, the strength of which did not differ significantly among matrix species or

251 later Aster life stages. The strength of the positive component was generally stronger than the

252 negative component (except for D. spicata) resulting in a positive net effect of the matrix species

253 on Aster. Previous studies have defined J. gerardi to be the "keystone facilitator" in this system

254 (Hacker and Gaines 1997). The strength of the facilitative component was as strong for $D$.

255 spicata and $S$. patens as it was for J. gerardi, suggesting that other matrix species can play a

256 similar functional role as $J$. gerardi.

257 Thinning $J$. gerardi blades by $50 \%$ significantly increased light availability to Aster

258 transplants but had no effect on salinity levels or Aster growth rates. Adult Aster growth in the

259 thinning plots was similar to growth in intact vegetation. The relatively weak (but not

260 significantly different) competitive effect of $J$. gerardi may in part be explained by the fact that it

261 grows and flowers earlier than the two grass species, and then dies back relatively early in the

262 growing season. This could reduce competition with forbs later in the summertime. Moreover,

263 the blades of $J$. gerardi tend to decompose rapidly, thus it does not form the dense thatch of

264 standing dead biomass, which is characteristic of both $S$. patens and D. spicata canopies. These

265 traits could reduce the strength of the positive and negative effects of $J$. gerardi on its neighbors.

266 In any case, the fact that $S$. patens, J. gerardi, and D. spicata reduce salinity to similar levels and

267 positively affect Aster growth to a similar degree suggests that all three species serve a strong

268 facilitative function in New England salt marshes. Thus, in this system the role of matrix species

269 as facilitators appears to be largely redundant. This is consistent with the hypothesis that species

270 from the same functional group have similar effects on other functional types within the same

271 community; however, we expect that other functional groups, such as forbs or shrubs, are likely 
272 to have different net effects (and relative contributions of competitive and facilitative

273 components).

274 The interpretation of our experiment assumes that all grass and rush matrix species share

275 a common mechanism of facilitation of marsh forbs - the reduction of soil salinity by shading

276 the substrate. However, some marsh matrix species also aerate the soil and hide neighbors from

277 herbivores (Ellison 1987, Hacker and Bertness 1999), which could serve as other mechanisms

278 for enhanced forb fitness. The same is true in many cases of plant-plant competition because

279 neighboring individuals are often simultaneously competing for multiple resources (e.g. light,

280 water, nutrients, and even space in one sense). Including more than one facilitation or

281 competition mimic treatment to simulate the effects of other facilitative or competitive

282 mechanisms could be used to tease part the strength and context specificity of each individual

283 mechanism. On the other hand, if the main interest is to determine the cumulative effect of all

284 facilitative or competitive mechanisms, the interaction mimics will have to be designed to

285 include all known mechanisms.

We found little difference in the effects of matrix species on the performance of Aster at

287 different life history stages. For example, there were no differences between either raw growth rates or interaction component strengths between juvenile and adult Aster. Mortality of seedlings in $J$. gerardi removal plots was $100 \%$, and thus interaction component strengths could not be calculated for this life stage. However, the high mortality clearly indicates that there is a strong

291 and critical facilitative effect of matrix species on this forb during the earliest life stages, a

292 finding concordant with other empirical studies (e.g. Kennedy and Bruno 2000). One of the

293 largest drawbacks of our experiment was the high within-treatment variance that reduced our

294 power to detect differences among treatments. Statistical power could be improved by increasing 
295 the sample size, however, under conditions where mortality of individuals may be exceedingly

296 high, as found for the seedling life stage in the present study, we suggest that within-treatment

297 variability could be reduced by setting up replicate response individuals (here, Aster transplants)

298 in each plot. For individual-level response variables like growth or fecundity, a plot-wide mean

299 could be calculated. This approach would also allow for the calculation of population-level

300 parameters such as percent survivorship and the inclusion of species especially susceptible to

301 environmental stress (because even total mortality in the neighbor removal treatment would

302 produce a continuous variable which is necessary for the calculation of component strengths).

303

304 CONCLUSION

305 Despite the difficulties involved, studies designed to tease apart the importance of positive and

306 negative components of interactions and their contingencies represent an exciting venue of

307 research with the potential to greatly expand our understanding of community organization.

308 Understanding such issues is not just an academic exercise - it is essential in order to predict how

309 natural communities and their component parts respond to environmental heterogeneity.

310 Furthermore, we cannot predict how the structure and organization of natural communities will

311 respond to climate change and anthropogenic stresses until we understand how different

312 components of the species interactions respond to such changes (Bertness et al. 1999a).

313

314

315 


\section{Literature Cited}

317 Altieri, A. H., and J. van de Koppel. 2014. Foundation species in marine ecosystems. Marine 318 Community Ecology and Conservation:37-56.

319 Altieri, A. H., B. R. Silliman, and M. D. Bertness. 2007. Hierarchical Organization via a

$320 \quad$ Facilitation Cascade in Intertidal Cordgrass Bed Communities 169.

321 Angelini, C., T. van der Heide, J. N. Griffin, J. P. Morton, M. Derksen-Hooijberg, L. P. M.

322 Lamers, A. J. P. Smolders, and B. R. Silliman. 2015. Foundation species' overlap enhances

323 biodiversity and multifunctionality from the patch to landscape scale in southeastern United

324 States salt marshes. Proceedings of the Royal Society B: Biological Sciences

$325 \quad 282: 20150421$.

326 Bertness, M. D. 1989. Intraspecific competition and facilitation in a northern acorn barnacle 327 population.

328 Bertness, M. D. 1991. Interspecific interactions among high marsh perennials in a New England 329 salt marsh.

330 Bertness, M. D., and A. M. Ellison. 1987. Determinants of pattern in a New England salt marsh $331 \quad$ plant community.

332 Bertness, M. D., L. Gough, and S. W. Shumway. 1992. Salt tolerances and the distribution of 333 fugitive salt marsh plants.

334 Bertness, M. D., and E. Grosholz. 1985. Population dynamics of the ribbed mussel, Geukensia 335 demissa: The costs and benefits of an aggregated distribution. Oecologia 67:192-204.

336 Bertness, M. D., and S. D. Hacker. 1994. Physical Stress and Positive Associations Among 337 Marsh Plants. The American Naturalist 144:363.

338 Bertness, M. D., G. H. Leonard, J. M. Levine, and J. F. Bruno. 1999a. Climate-driven 
interactions among rocky intertidal organisms caught between a rock and a hot place.

$340 \quad$ Oecologia 120:446-450.

341 Bertness, M. D., G. H. Leonard, J. M. Levine, P. R. Schmidt, and A. O. Ingraham. 1999b.

342 Testing the relative contribution of positive and negative interactions in rocky intertidal 343 communities. Ecology 80:2711-2726.

344 Bertness, M. D., and S. W. Shumway. 1993. Competition and facilitation in marsh plants. $345 \quad$ American naturalist 142:718-724.

346 Bertness, M. D., and S. M. Yeh. 1994. Cooperative and competitive interactions in the 347 recruitment of marsh elders. Ecology 75:2416-2429.

348 Brewer, J. S., and M. D. Bertness. 1996. Disturbance and intraspecific variation in the clonal 349 morphology of salt marsh perennials. Oikos 77:107-116.

350 Brewer, J. S., J. M. Levine, and M. D. Bertness. 1997. Effects of biomass removal and elevation 351 on species richness in a New England salt marsh. Oikos 80:333-341.

352 Brewer, J. S., J. M. Levine, and M. D. Bertness. 1998. Interactive effects of elevation and burial 353 with wrack on plant community structure in some Rhode Island salt marshes. Journal of $354 \quad$ Ecology 86:125-136.

355 Bruno, J. F., and C. W. Kennedy. 2000. Patch-size dependent habitat modification and 356 facilitation on New England cobble beaches by Spartina alterniflora. Oecologia 122:98$357 \quad 108$.

358 Callaway, R. M. 1994. Facilitative and interfering effects of Arthrocnemum subterminale on 359 winter annuals. Ecology 75:681-686.

360 Callaway, R. M. 1995. Positive interactions among plants. Botanical Review 61:306-349.

361 Callaway, R. M., N. M. Nadkarni, and B. E. Mahall. 1991. Facilitation and interference of 
362 Quercus douglasii on understory productivity in central California.

363 Callaway, R. M., and L. R. Walker. 1997. Competition and facilitation: A synthetic approach to 364 interactions in plant communities.

365 Claus Holzapfel, A., and B. E. Mahall. 1999. Bidirectional facilitation and interference between 366 shrubs and annuals in the Mojave Desert. Ecology 80:1747-1761.

367 Connell, J. H. 1961. The influence of interspecific competition and other factors on the 368 distribution of the barnacle Chtalamus stellatus. Ecology 42:710-723.

369 Crotty, S. M., and M. D. Bertness. 2015. Positive interactions expand habitat use and the realized $370 \quad$ niches of sympatric species. Ecology 96:2575-2582.

371 Dayton, P. K. 1975. Experimental evaluation of ecological dominance in a rocky intertidal algal 372 community. Ecological Monographs 45:137-159.

373 Ellison, A. M. 1987. Effects of competition, disturbance, and herbivory on Salicornia europaea.

374 Gómez-Aparico, L., R. Zamora, J. M. Gómez, J. A. Hódar, and J. Castro. 2004. Applying plant 375 facilitation to forest restoration: A meta-analysis of the use of shrubs as nurse plants. $376 \quad$ Ecological Applications 14:1118-1138.

377 Greenlee, J. T., and R. M. Callaway. 1996. Abiotic Stress and the Relative Importance of 378 Interference and Facilitation in Montane Bunchgrass Communities in Western Montana. $379 \quad$ The American Naturalist 148:386.

380 Hacker, S. D., and M. D. Bertness. 1999. Experimental evidence for factors maintaining plant $381 \quad$ species diversity in a New England salt marsh. Ecology 80:2064-2073.

382 Hacker, S. D., and S. D. Gaines. 1997. Some implications of direct positive interactions for 383 community species diversity.

384 Kennedy, C. W., and J. F. Bruno. 2000. Restriction of the Upper Distribution of New England 
385 Cobble Beack Plants by Wave-Related Distrubance. Journal of Ecology2 88:856-868.

386 Kraft, N. J. B., G. M. Crutsinger, E. J. Forrestel, and N. C. Emery. 2014. Functional trait

387 differences and the outcome of community assembly: an experimental test with vernal pool

$388 \quad$ annual plants 123:1391-1399.

389 Leger, E. A., and E. K. Espeland. 2010. The shifting balance of facilitation and competition

390 affects the outcome of intra- and interspecific interactions over the life history of California

391 grassland annuals. Plant Ecology 208:333-345.

392 Leonard, G. H. 1999. Positive and negative effects of intertidal algal canopies on recruitment and 393 survival of barnacles. Marine Ecology Progress Series 178:241-249.

394 Leonard, G. H. 2000. Latitudinal variation in species interactions: A test in the New England 395 rocky intertidal zone. Ecology 81:1015-1030.

396 Lively, C. M., and P. T. Raimondi. 1987. Desiccation, predation, and mussel-barnacle

397 interactions in the northern Gulf of California. Oecologia 74:304-309.

398 Miller, W. B., and F. E. Egler. 1950. Vegetation of the Wequetequock-Pawcatuck tidal marshes.

399 Ecological Monographs 20:143-172.

400 Moore, A. F. P., and J. E. Duffy. 2016. Foundation species identity and trophic complexity affect 401 experimental seagrass communities. Marine Ecology Progress Series 556:105-121.

402 Muller, C. H. 1953. The association of desert annuals with shrubs. American Journal of Botany $403 \quad 40: 53$.

404 Niering, W. A., and R. S. Warren. 1980. Vegetation Patterns and Processes in New England Salt 405 Marshes. BioScience 30:301-307.

406 Niering, W. A., R. H. Whitaker, and C. W. Lowe. 1963. The saguaro: a population in relation to 407 environment. Science 142:15-23. 
408 Nixon, S. W. 1982. The ecology of New England high salt marshes: a community profile. U.S.

409 Fish Wildl. Service Biol. Rep.:70.

410 Rand, T. a. 2000. Seed dispersal, habitat suitability and the distribution of halophytes across a

411 salt marsh tidal gradient. Journal of Ecology 88:608-621.

412 Rand, T. a, S. M. Louda, K. M. Bradley, and K. K. Crider. 2015. Effects of invasive knapweed

413 (Centaurea stoebe ssp. micranthos) on a threatened native thistle (Cirsium pitcheri) vary

414 with environment and life stage. Canadian Journal of Botany 93:543-558.

415 Rojas-Sandoval, J., and E. Meléndez-Ackerman. 2012. Effects of an invasive grass on the

416 demography of the Caribbean cactus Harrisia portoricensis: Implications for cacti

417 conservation. Acta Oecologica 41:30-38.

418 Shumway, S. W., and M. D. Bertness. 1992. Salt stress limitation of seedling recruitment in a 419 salt-marsh plant community. Oecologia 92:490-497.

420 Stachowicz, J. J. 2001. Mutualisms, positive interactions, and the structure of ecological $421 \quad$ communities. BioScience 51:235-246.

422 Thomson, D. 2005. Measuring the effects of invasive species on the demography of a rare 423 endemic plant. Biological Invasions 7:615-624.

424 Yelenik, S. G., N. DiManno, and C. M. D’Antonio. 2015. Evaluating nurse plants for restoring 425 native woody species to degraded subtropical woodlands. Ecology Evolution:1294. 426 


\section{Figure 1}

\section{Experimental design}

Figure 1. Photograph of a treatment block using J. gerardi as the transplanted matrix species with four experimental treatment plots (see labels) and a single Aster adult transplanted into each treatment plot. Photo credit: John Bruno.

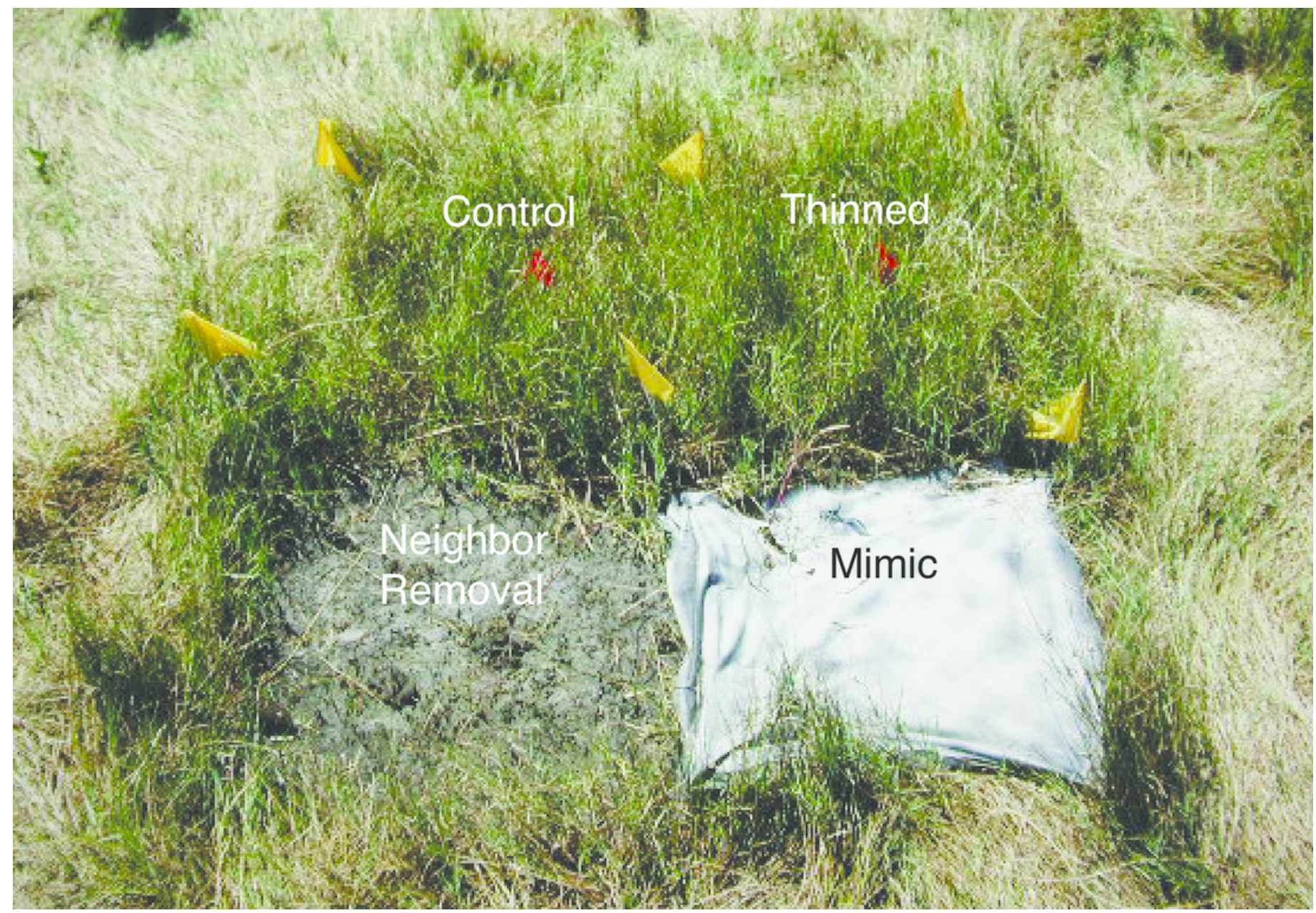




\section{Figure 2}

Environmental conditions and starting plant biomass.

Figure 2. Effects of the matrix species (left panels) and experimental manipulations (right panels) on environmental conditions (data are means $\pm 1 \mathrm{SE}$ from July measurements; August data are not presented but were nearly identical) and initial Aster biomass. 

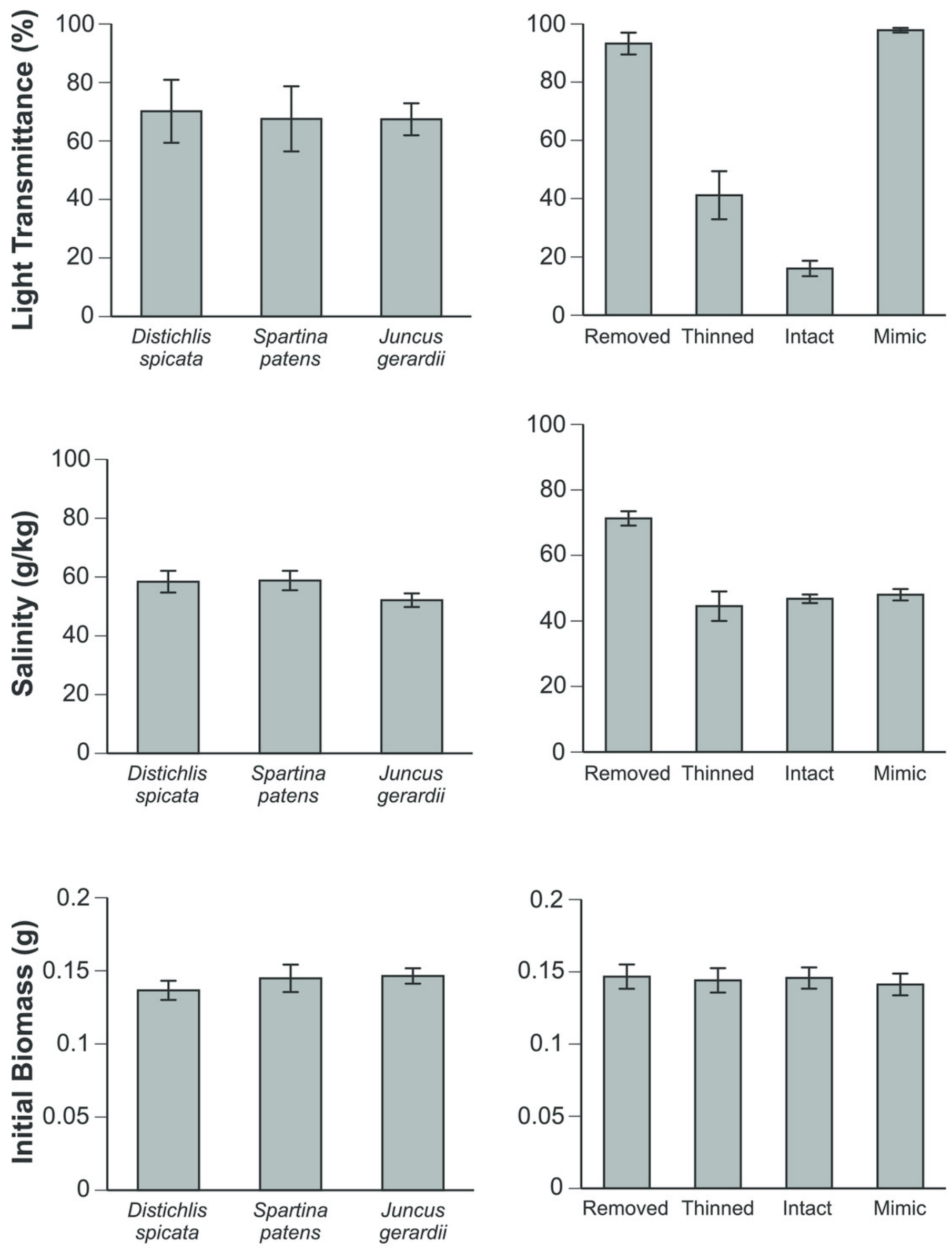


\section{Figure 3}

Final Aster biomass.

Figure 3. Final biomass of adult Aster plants after 75 days in the experimental treatments and different matrix species. The thinned treatment, in which grass shoot density was reduced by $50 \%$, was only applied in the plots with Aster adults transplanted into the $\mathrm{J}$. geradi matrix. Data are means $\pm 1 \mathrm{SE}$. Final Aster biomass varied significantly $(P<0.05)$ among treatments for all three matrix species (One-factor ANOVA).

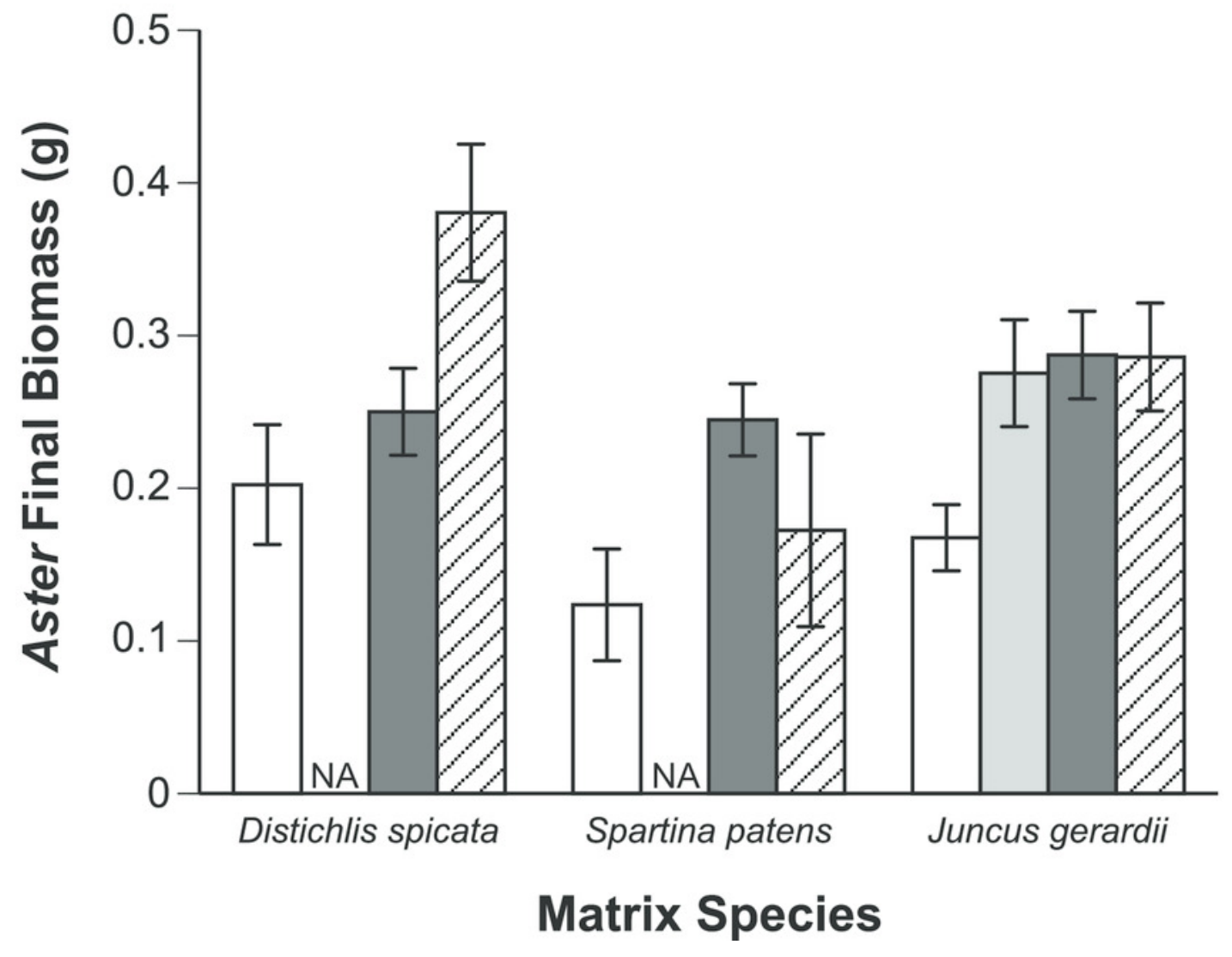

Neighbor

Treatment

$\square$ Removed

Thinned

Intact

C Mimic 
Figure 4

Species interaction components

Figure 4. Net, negative, and positive effects of three salt marsh matrix species on adult and juvenile Aster based on final biomass. Apparent differences in the strength of interaction components among the matrix species were not statistically significant ( $P>0.05, A N O V A)$.

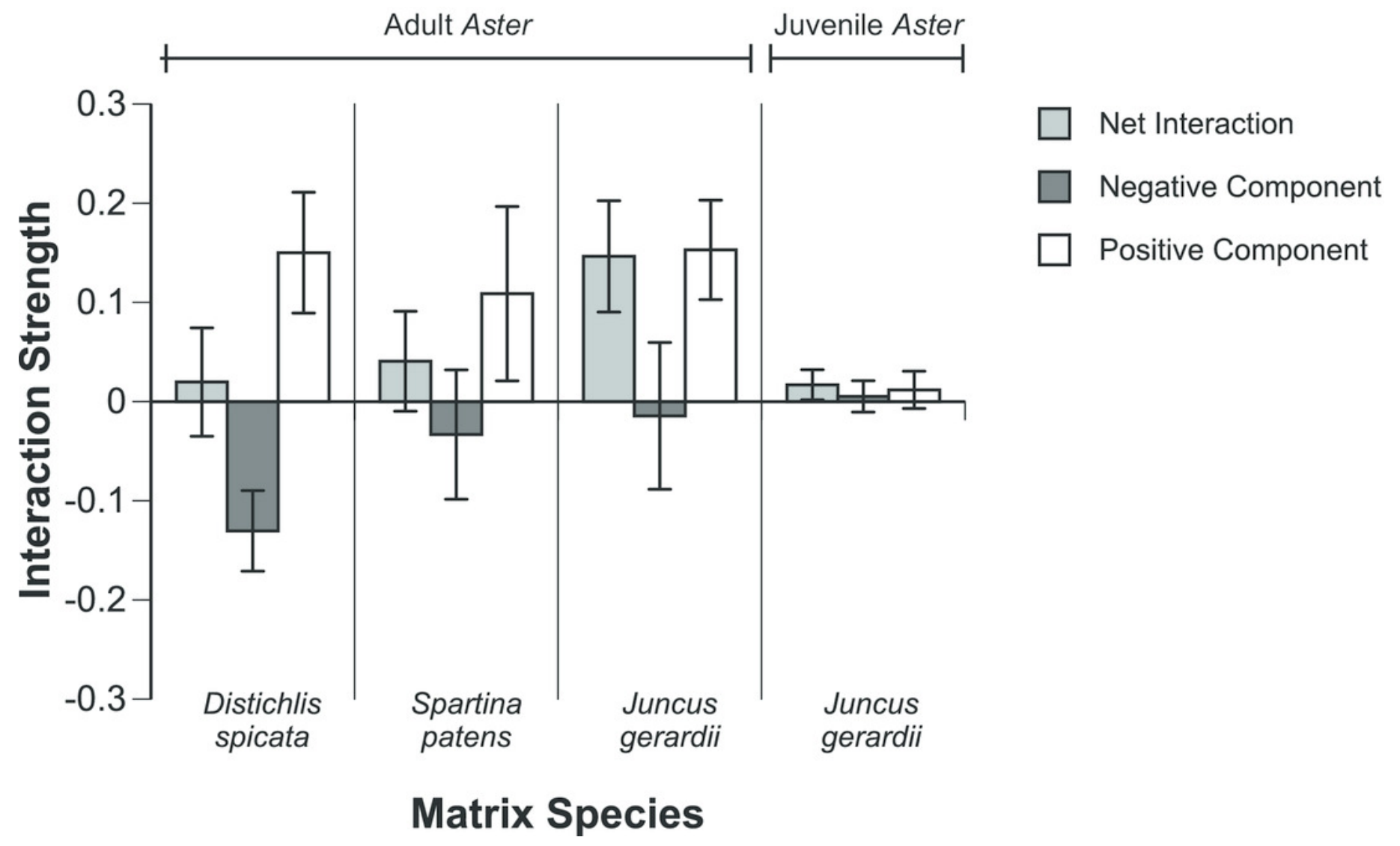

